\title{
What Kind of Mentoring Do We Need? A Review of Mentoring Program Studies for Medical Students
}

\author{
Yera Hur', Sun Kim² and Keumho Lee ${ }^{1}$
}

${ }^{1}$ Department of Medical Education, Konyang University College of Medicine, Daejeon, and ${ }^{2}$ Department of Medical Education, The Catholic University of Korea School of Medicine, Seoul, Korea

\section{우리에게는 어떠한 멘토링이 필요한가? 의과대학생을 위한 멘토링 프로그램의 연구동향 고찰}

${ }^{1}$ 건양대학교 의과대학 의학교육학교실, ${ }^{2}$ 가톨릭대학교 의과대학 의학교육학과

\section{허예라 ${ }^{1}$, 김 선 ${ }^{2}$, 이금호 $^{1}$}

Nearly every medical school in Korea has a student advisory program, regardless of its form or method, but it is plagued by efficiency. To examine efficient means of delivering student advisory programs, we chose 'mentoring' as one solution and reviewed the concepts of a mentor and mentoring, the qualities and roles of a mentor, and examples of national and international cases of mentoring. The concept of mentoring is diverse, but it connotes and stresses aspects, such as individual guidance, tutoring, life coaching, and role modeling. We conclude that the quality of many student advisory programs can be elevated by providing holistic and systematic guidance that meets the demands of the mentees; giving individual, continuous, and intimate coaching; and guiding a balanced academic and social life and career, which will develop good doctors who can provide a holistic health care.

Key Words: Mentoring, Program, Medical students

\section{서론}

최근 국내에서 시행한 역학조사에 따르면[1], 의과대학생 10 명 중 1 명이 평생 동안 우울장애를 경험한 적이 있으며, 자 살계획을 경험한 경우는 $4.2 \%$, 자살시도를 한 경험이 있는 학 생은 $2.2 \%$ 로 나타나 국내 의과대학생들의 정신건강문제가 간 과할 수 없는 수준임을 알 수 있다. 또한 이 연구에서 의과대
학생들의 우울증 발병 원인으로 스트레스가 가장 큰 영향을 미치는 것으로 나타났으며, 의과대학생 중 약 $16 \%$ 는 유급을 경험하며[2], 성적과 같은 학업관련 요인이 가장 큰 스트레스 로 작용하는 것으로 보고되고 있지만[1,3,4], 불충분한 휴식 시간, 자아존중감이 낮은 경우도 중증 스트레스의 관련 요인 으로 나타나고 있다[5].

Saipanish [6]의 연구에서도 일반적으로 $60 \%$ 이상의 의과 대학생들은 심각한 스트레스를 경험하고 있으며, $80 \%$ 를 웃도
Received: January 31, 2013 • Revised: February 2, 2013 • Accepted: February 5, 2013 Corresponding Author: Keumho Lee

Department of Medical Education, Konyang University College of Medicine, 158 Gwanjeodong-ro, Seo-gu, Daejeon 302-718, Korea

Tel: +82.42.600.6416 Fax: +82.42.600.6417 email: apri10401@konyang.ac.kr
Korean J Med Educ 2013 Mar; 25(1): 5-13. http://dx.doi.org/10.3946/kjme.2013.25.1.5 pISSN: 2005-727X eISSN: 2005-7288

(C) The Korean Society of Medical Education. All rights reserved. This is an open-access article distributed under the terms of the Creative Commons Attribution Non-Commercial License (http:// creativecommons.org/licenses/by-nc/3.0/), which permits unrestricted non-commercial use, distribution, and reproduction in any medium, provided the original work is properly cited. 
는 의과대학생들은 자신이 겪는 스트레스가 자신의 학업에 부정적인 영향을 끼친다고 보고될 정도로 의과대학생들이 지 각하는 스트레스는 매우 심각한 수준에 도달해 있다고 할 수 있다. 이렇게 국내외 의과대학생들의 스트레스, 우울증 등에 관한 연구들에서는 의과대학생들의 심리적 상태와 자살계획 등이 간과할 수 없는 문제임을 밝히고 있다. 몇몇 연구들에서 는 이를 해결할 방법을 제시하고는 있으나, 실제 교육현장에 서 제대로 적용되고 활용되지는 않고 있다. Frank et al. [7] 의 연구에서는 의과대학생들의 생활습관을 건강하게 만들면 적극적으로 건강한 생활습관에 대해 예방적 상담을 할 수 있 는 의사가 될 수 있다는 점을 강조하고 있다. 즉, 좋은 의사가 되기 위해서는 기본적으로 의사 자신부터 신체적 - 육체적으 로 건강해야 하는데 이를 위해 교육적인 측면에서 학생들에 게 도움을 줄 수 있는 한 가지 방법이 우리가 잘 알고 있는 학생생활상담 또는 의과대학에서 많이 실시하고 있는 지도교 수제도 혹은 담임반제도이다. 그러나 의과대학생의 $60 \%$ 이상 은 대학생활에서의 가장 심각한 문제로 학업의 어려움을 들 고 있으나, $67 \%$ 이상의 학생들은 이러한 어려움에 대한 도움 을 교수나 친구로부터 받지 못하고 있다고 응답하고 있다[8]. 많은 의과대학에서 지도교수제도나 담임반제도를 운영하고 있지만 이러한 프로그램이 제대로 운영되고 있지 못한 것이 다. 그런데 최근에 단순한 상담이나 만남 보다는 보다 체계적 인 학생관리 프로그램을 고민하는 조짐이 보이는데 그것이 멘토링(mentoring)이다.

그러나 의과대학생들의 멘토링 프로그램에 대한 선행 연구 는 매우 부족한데, Buddeberg-Fischer \& Herta [9]와 Frei et al. [10]의 연구를 보면 1996 2002년도와 2000 2008년도 사이의 관련 논문이 각각 6 편과 14 편 검색되어 프로그램 개발 에 대한 연구가 부족함을 시사하고 있다. 국내 선행 연구의 현 황은 더 열악하다. 우리나라의 대표적인 의학저널 검색엔진 인 KMbase (한국의학논문데이터베이스)를 사용하여 키워드 '멘토링'을 검색하면 13 편, 키워드가 제목에 포함된 경우는 겨 우 9편이며 이 중 의학과 관련된 연구논문은 한 편도 찾아볼 수 없다. 키워드를 '지도교수로 찾아보면, 총 52편의 논문 중 제목에 키워드를 포함한 논문은 4편이고 이 중 의학 관련 연 구논문은 1 편에 불과하다. 국내 선행 연구들은 연구 대상이나 방법과 내용이 모두 매우 제한적인데, 일부 연구에서 학생들
의 건강증진을 위한 프로그램을 운영한 결과[11]가 있었지만 이러한 연구 결과도 학생지도나 멘토링 프로그램과는 연계되 지 못했다. 이렇게 멘토링, 지도교수제 또는 학생지도와 관련 된 연구가 부족한 이유는 이러한 연구를 담당할 기구가 없고 의과대학이나 의학전문대학원에서 관련 프로그램을 제대로 운영하지 못하고 있는 이유도 한 몫을 하고 있을 수 있다.

대학생활을 통해 학생들은 고등학교 시기와는 질적으로 다 른 많은 새로운 유형의 압박감을 느끼게 되며, 대학생활을 통 해 자신의 진로에 대한 방향 설정과 더불어 전문적 정체감을 형성하게 된다[12]. 또한 의예과 과정생과 의학과(본과) 학생 들의 특성이 다르고, 고학년이 되면 선택 실습을 많이 하게 되 는 의과대학생들의 특성상 멘토의 부재는 전공 선택과 실습 준비에 있어서도 어려움을 초래할 수 있다[13]. 또한 저학년 보다는 고학년 학생이 더 우울하고 학업스트레스를 많이 받 고 있는데 이는 학년이 올라갈수록 학습량과 시험횟수의 증 가, 학습내용과 수준의 변화로 인한 것으로 볼 수 있다[14]. 따라서 학년의 특성, 즉 학습시기에 따른 차별화된 지도와 관 리, 다면적 상담, 입학부터 졸업까지 그리고 나아가 추후에는 전공의 및 의사가 되어서도 관리가 될 수 있는 총체적인 멘토 링 프로그램이 반드시 필요하다.

멘토링 프로그램은 학업의 수월성을 지원할 뿐만 아니라 팀협동학습의 분위기를 창출하고 경험할 수 있으며, 교수와 학생 간의 보다 개방적이고 자연스러운 관계를 형성할 수 있 고, 학교 차원에서는 학생들에게 지원적인 환경조성을 함으 로써 결과적으로는 학생들의 학업성취도가 높아지고 수행능 력이 개선될 수 있다는 큰 장점이 있다[15]. 멘토링은 멘토의 역할을 하는 교수에게도 긍정적인 효과가 있는데 개인적 만 족감, 개인적 성취감, 창조적 시너지 효과, 네트워킹, 동기유 발, 자기개발, 학교에 대한 만족도 상승, 스트레스와 역할 갈 등 저하, 전문가로서의 자신감 고취, 정체성 및 전문성 개발 등이 있어[16] 프로그램을 제공하는 공급자와 수요자 모두에 게 득이 될 수 있는 과정이다.

이러한 배경에서 이 연구는 멘토링에 대한 개념부터 살펴보 고자 한다. 이를 위해 첫째, 멘토(mentor), 멘티(mentee), 멘토 링(mentoring)의 개념을 살펴보고, 둘째, 멘토링 프로그램의 핵심인 멘토의 자질과 역할을 알아보며, 마지막으로 멘토링의 유형과 모형을 국내·외 사례들을 통해 살펴보고자 한다. 


\section{멘토, 멘티와 멘토링의 개념}

현대사회에서 '멘토링'의 개념은 너무나 다양하게 사용되고 정의되기 때문에 이를 정의 내린다는 것 자체가 무의미하다 는 의견도 있다[17]. 우리나라 의학교육 현장과 다른 고등교 육기관에서 사용하는 '지도교수라는 용어는 그 역할과 목적 에 따라 서로 다른 개념으로 사용되고 있다. 흔히 상담자, 개 인교수, 멘토라는 용어가 구분 없이 사용되는 경우가 많은데, 실제로 이들 간에는 명백한 개념 차이가 있다[18].

먼저, 멘토링 과정은 1970년대에 미국의 기업체에서 개발되 어 사용되기 시작한 것으로 1990 년대까지 다양한 분야에서 멘 토링 프로그램을 도입하였는데 간호학 분야에서 가장 많이 활 용되었다. 멘토링 프로그램이 의과대학생과 의사들에게 적용 되기 시작한 것은 1990년대 말부터이다[9]. 그 이후 멘토링의 개념이 매우 빠르게 확산되었는데, Garmel [19]이 정리한 멘 토링의 개념은 멘토(지도교수)의 경험과 지혜를 활용하여 학 생이 자기통찰을 하는 과정임과 동시에 학생에게 지원적이고 보호적인 지지를 해주는 과정으로 보았다. 따라서 성공적인 교 수(멘토, mentor)-학생(멘티, mentee) 지도 관계를 위해서는 양자 간의 적극적인 참여가 있어야 한다고 강조하였다.

Shea \& Gianotti [20]는 멘토링, 멘토 그리고 멘티에 대한 개념을 다음과 같이 설명하였다. 멘토링은 개인적이면서도 전문적인 관계를 말하는데, 멘토링의 주목표는 보다 경험이 많은 사람이 경험이 적은 사람의 발달을 돕는 과정이다. 멘토 링은 높은 수준의 대인 의사소통 능력이 필요하며 관계 바탕 으로 이루어져야 하며, 공식 또는 비공식적 지식의 전달, 사회 적 관계 또는 네트워크 형성, 심리적 또는 사회적 지원을 포함 한다. 따라서 가장 훌륭한 멘토링은 한 개인이 자신의 삶에서 필요한 것들을 얻게 함으로써 미래에 보다 큰 수행능력, 결과 물, 성취를 할 수 있도록 도와주는 것이다. 멘토는 신뢰로운 조언자라 할 수 있는데, 삶이나 전문영역에서 보다 경험이 많 은 사람이다. 멘토는 멘티의 역할모델이 될 수 있는 사람이며, 멘티의 학업뿐만 아니라 진로에서도 개인적인 도움을 줌으로 써 멘티의 네트워크 형성을 향상시켜준다. 멘토는 일대일 관 계로 인해 멘티에게 장기적인 영향을 미치고, 멘티에게 보다 깊이 있는 지식과 예리한 통찰력, 폭넓은 시각, 많은 지혜, 넓
은 관계 형성을 해 줄 수 있는 사람을 의미한다. 멘티는 멘토 링 관계에서 수혜 받는 사람을 말하는데, 전통적으로는 멘토 가 횔씬 나이가 많았으나 최근에는 나이가 문제되지 않고 있 다. 멘티는 멘토보다 경험이 적은 피보호자로, 멘토링을 통해 얻은 지식을 내면화하고, 이를 효과적으로 사용하며, 기술을 향상시키고, 통찰력을 얻고, 시각을 넓히며, 지혜를 얻고자 노 력하는 사람을 칭한다. 멘토링의 유형은 시간이 흐름에 따라 변화하였지만 그 중요성과 영향력은 변하지 않고 있다[20].

기타 몇 가지 다른 문헌들을 살펴보면 멘토링은 풍부한 경 험과 지혜를 겸비한 신뢰할 수 있는 사람이 일대일 지도와 조 언을 하는 것이며[21], 멘토는 경험이 많은 사람으로 경험이 적은 아랫사람, 즉 멘티의 성장과 발달을 최대한 돕기 위해 일 대일로 지속적인 관계 속에서 친구, 스승, 모범인물, 안내자, 조언자, 상담자 등의 역할을 수행하는 것으로 보았다. 멘토링 관계는 멘토와 멘티가 상호관심, 상호신뢰, 상호존경을 바탕 으로 지식이나 기술을 가르치는 역할을 넘어서서 멘티의 전 반적인 자아실현에 초점이 맞춰지는 과정으로 설명하고 있다 [22]. 멘토링의 대상이 되는 멘티는 프로테제(protégé), 멘토 리(mentoree) 등 다양한 용어로 혼용되어 사용되고 있다. 프 로테제는 불어로 '피보호자', '부하, '제자라는 의미이며, 멘토 리는 주로 영국에서 사용되는 용어로 멘티와 마찬가지로 도 움을 받는 사람이라는 의미가 있다.

\section{멘토의 자질과 역할}

선행 연구나 문헌 조사를 통해 밝혀진 멘토의 역할에 대한 내용을 몇 가지 살펴보면, Frei et al. [10]은 멘토는 학생의 전문성 개발과 개인적 성장을 적극적으로 도와주는 사람으로 보았고, Souba [23]는 'mentor'의 앞 글자들을 따서 멘토의 역 할을 다음과 같이 설명하고 있다. 1) Motivate: 학습자의 동기 를 유발시켜주기, 2) Empower and encourage: 능력을 개발 할 수 있도록 지지하고 격려해주기, 3) Nurture self confidence: 자신감을 갖도록 양육해주기, 4) Teach by example: 모범이 되어 가르치기, 5) Offer wise counsel: 지 혜로운 상담가가 되기, 6) Raise the performance bar: 학습 자의 수행능력을 향상시켜주기. Ramanan et al. [24]은 멘토 
는 오랜 기간 동안 지속적으로 지도학생의 잠재력을 일깨워주 고 그 잠재력을 최대한 발휘할 수 있도록 지도하여 학습자 자 신이 세운 목표에 도달할 수 있도록 해주는 역할을 한다고 주 장하였다. $\operatorname{Kram}$ [25]은 지도교수가 해야 할 주요 역할로 다음 과 같이 두 가지를 제시하였는데 그 내용이 멘토의 역할과 매 우 흡사하다. 첫째, 학생이 의사라는 직업에 대해 이해하고, 이를 수행할 수 있도록 준비를 시키며, 스스로의 자질을 개발 해 나가도록 동기를 유발시키는 역할이다. 이러한 진로개발 안내자의 역할에는 선배의사로서 전문적인 지식이나 기술을 가르치고, 직업적으로 부당한 일에 개입되지 않도록 방어해주 며, 보다 건설적이며 도전할 만한 직업적 영역에 대한 가능성 을 제시하는 것을 포함한다. 둘째, 심리적 지지자로서의 역할 (psychological function)로 이를 위해서는 교육과정이나 개 인적 삶에서의 갈등과 스트레스를 해소하도록 도와주며, 의사 로서 또는 한 인간으로서의 삶에 대한 자신감과 정체성을 확 립하도록 지지해주어야 한다[18]. Feldman [26]은 멘토는 멘 티의 욕구와 필요에 따라 멘티를 안내하고 지지해야하는 역할 이며, 멘티의 성장을 도모하며, 멘티와 합의한 학습계획에 따 라 구체적인 지도를 해주며, 위계질서를 벗어난 관계를 형성 하며, 멘티와 관련한 내용은 반드시 비밀 보장을 해주어야 한 다고 보았다. Harvard Business School [27]에서는 멘토링의 역할을 크게 직업관련 기능(career funtions), 심리사회적 기 능(psychosocial personal functions) 두 가지로 구분하여 설 명하고 있다. 직업관련 기능은 스폰서십(sponsorship), 코칭 (coaching), 보호(protection), 도전(challenge), 노출과 가시 성(exposure and visibility) 등이며, 조직 내에서의 프로테제, 즉 멘티의 능력과 지위를 높이는 것을 목표로 한다. 반면 심리 사회적 기능은 역할모델(role modeling), 상담(counseling), 적응과 확인(acceptance and confirmation), 친밀감(friendship)으로 설명하고 있는데 멘티의 내적인 측면에서의 멘토링 을 하는 것을 의미한다.

\section{멘토와 코치(Coach)의 다른 점}

멘토링의 개념이 우리나라에서 확산되기 이전에 먼저 나온 유사한 개념이 '코칭(coaching)'이다. 우리나라에는 이미 많
은 코칭기관이 존재하며 다양한 코칭 프로그램들을 다양한 대상들에게 제공하고 있다.

Harvard Business School은 멘토링에 대한 많은 자료와 노하우를 가지고 있는데, 사람들이 많이 혼동하거나 비교하 는 멘토링과 코칭에 대해 그 차이를 구체적으로 설명하고 있 다. 멘토링은 코칭과는 그 성격과 내용적인 면에서 매우 다른 데, 코칭의 목적은 코칭 대상자의 적절하지 않은 행동을 고치 거나 수행능력을 개선하거나 새로운 기술을 가르쳐 주는 데 있다. 반면, 멘토링은 멘토링 대상자의 개인적인 성장을 지지 하고 안내해주는 데 가장 큰 목적이 있다. 멘토링은 멘토와 멘 티 모두 자발적인 지원자들이어야 하지만 코칭은 그렇지 않 다. 코칭은 즉시적인 문제를 다루고 학습을 하지만 멘토링은 개인의 장기적인 진로 개발에 초점을 둔다. 코치의 역할은 학 습자에게 적절한 가르침과 피드백을 핵심으로 하지만 멘토링 에서의 멘토의 역할은 화자이기 보다는 경청하는 자이며 역 할모델이 되어주고 의견을 제시하는 역할을 한다. 또한 코칭 은 필요에 따라 수행되는 것이며 주로 단기간 목표를 두지만 멘토링은 장기적인 목표를 두고 진행한다. 코칭에서의 코치 는 대상자의 상사이지만 멘토링에서의 멘토는 그러한 경우가 드물며 이를 지양한다[27].

\section{멘토링의 유형과 모형}

국내외에서 활용하고 있는 다양한 멘토링의 유형과 모형을 살펴보면 다음과 같다.

\section{1. 외국 사례}

멘토링의 유형이나 모형 중 의과대학생을 대상으로 한 문 헌은 쉽게 찾아보기 어렵다. 외국 문헌에서 ‘멘토링’이라 하면 대부분 신임교수나 학교 선생에게 필요한 멘토링을 많이 다 루고 있기 때문이다. 연구기간 동안 수집한 자료를 토대로 연 구 결과에 도움이 될 만한 몇 가지 내용을 정리해 보면 다음과 같다. Ensher \& Murphy [28]는 전통적인 멘토링의 유형과 현대적인 멘토링(파워 멘토링) 유형의 차이를 설명하고 있다. 전통적인 멘토링은 단기간 성공을 목적으로 하며 멘토의 희 망과 요구에 따라 진행되는데 반해 현대적인 멘토링은 장기 
간의 성공 계획을 목적으로 멘토보다는 프로테제, 즉 멘티를 중심으로 이루어진다. 이 두 가지 멘토링 모형에서 '파워 멘토 링'이 시사하는 바는 멘토링이란 장기적인 프로그램으로 운영 되는 것이 좋으며, 멘티의 욕구와 의견을 충분히 반영하고 필 요한 경우 한 사람의 멘토가 아닌 다양한 전공분야의 전문가 를 연결시켜 줄 수 있어야 한다는 것이다. 본 연구에서는 전통 적인 접근방법보다는 현재적인 접근방법의 유형에 맞는 모형 과 내용을 개발하는 것이 보다 적절하다고 판단된다.

뉴욕의과대학(NYU School of Medicine)에서 배포하고 있는 멘토링 안내자료를 보면 멘토링의 유형을 4가지로 설명 하고 있다[29]. 첫째는 'director mentor' 유형으로 공식 또는 비공식적으로 형성될 수 있으며 이 유형의 멘토링은 전문성 개발, 지식 전달, 역할모델 제공, 지지와 격려 등을 주요 내용 을 한다. 'Peer mentor' 유형은 말 그대로 동료가 멘토가 되는 것으로 위계질서가 없으며 정서적인 공감대 형성과 신뢰를 바탕으로 관계 형성이 가능하지만 경험이나 지혜, 전문성 개 발에는 한계가 있다. 'Multiple mentors' 유형은 여러 명의 멘 토를 두는 것으로 멘티의 다양한 욕구를 충족시키는 데에는 매우 유용한 유형이다. 'External mentor'의 경우 학교 밖에 서 자신의 멘토를 찾는 것으로 자신이 원하는 자질을 가진 보 다 정확한 멘토를 확보할 수 있다는 장점이 있고 서로 이해관 계에서 갈등이 빚어지지 않는다는 점도 매력적이라 할 수 있 다.

\section{2. 국내 사례}

국내 사례의 경우 몇 가지 연구에 도움이 될 만한 모형을 찾을 수 있었다. Lee et al. [30]은 원격 · 성인학습자를 위한 멘토링 프로그램 요구 분석과 모형 개발을 시도하였는데, 원 격대학생들이 교육의 대상이므로 멘토링의 목표가 중도탈락 방지, 학습동기 고취, 학생회와 학습동아리 활성화라고 하여 일반적인 대학교육 목표와는 조금 다르다는 것을 알 수 있다. 그러나 멘토링의 내용적인 측면에서 보면 크게 대학생활 적 응, 학습안내와 지도 그리고 상담과 진로지도라는 일반적인 멘토링 목적이나 내용과 흡사한 부분이 있다. 한편, Kan [31] 의 연구에서 밝힌 멘토링의 모형은 크게 두 가지인데, 하나는 학습지도형 멘토링 모형(Appendix 1)이고 다른 하나는 진로 지도형 멘토링 모형이다(Appendix 2). 이 모형은 멘토링의
지원체계를 설명하고, 기대효과, 참여 목적, 역량, 기능, 참여 동기 요소를 멘토와 멘티의 입장에서 정리하였다. 학습지도 형 멘토링 모형의 경우 멘토의 시각에서 보면 기대효과가 학 습력 제고와 취업률이지만 진로지도형은 취업률과 글로벌 인 재상이 목표이다. 또한 멘토링의 참여 목적에서도 학습지도 형은 멘티의 시각에서 보면 관련과목 성적을 향상하고 학습 방법을 습득하는 것이지만 진로지도형 모형에서는 다양한 경 험과 진로설정, 인간관계 형성 그리고 학교생활에 필요한 정 보를 획득하는 것이다. 학습지도형 멘토링 모형에서 멘토의 기능은 가르치고, 관계 형성을 하며, 학습을 지원하고, 학습법 에 대한 상담을 제공하고, 선후배 간의 유대감을 상승시킨다 면, 진로지도형 모형에서의 멘토는 코칭과 더불어 대학생활 적응과 설계를 지도하고, 진로와 취업 정보, 자격증이나 공모 전 정보 제공, 성공사례 제공, 인간관계 형성, 그리고 자기 성 찰의 기회를 갖도록 하는 것이다. Kan [31]의 멘토링 모형은 학습지도의 측면과 진로지도의 측면을 구분하여 체계적인 모 형을 제안했다는 점에서는 매우 훌륭한 모델이라 할 수 있다.

\section{결론}

본 연구는 멘토, 멘토링, 멘토링 프로그램에 대한 문헌연구 를 통해 그 개념과 연구동향을 살펴보았다. 이러한 연구결과 를 통한 결론과 의과대학생들을 위한 멘토링 프로그램 개발 방안에 대해 모색해보면 다음과 같다.

첫째, 우리나라 의과대학에서 실시하고 있는 지도교수제도 나 담임반제도가 추구하고자 하는 목적이나 목표는 이상 살 펴본 멘토, 멘티, 멘토링에 대한 개념과 유사할 수 있으나 현 실에서 진행되고 있는 지도교수제도나 담임반제도의 모습과 는 거리가 있다. 우리나라 의과대학의 지도교수제도에 대한 몇몇 연구들에서도 현행 지도교수제도의 문제점이 지적되고 있다. 한 연구에 따르면 교수와 학생들 사이에 지도교수제도 의 목적이 상이하게 나타나는데, 지도교수제도의 목적에 대 해 교수들은 바람직한 의사로서의 태도 교육이라고 응답하는 반면, 학생들은 교수와 학생관계의 증진과 친목이 가장 중요 하다고 응답하였다[18]. 또한 이 연구에서 교수의 시간과 경 험 부족, 대학차원에서의 행정적, 재정적 지원 미비 등으로 의 
과대학에서의 지도교수제가 유명무실한 제도가 되고 있다는 지적을 하고 있다. Ahn [32]의 연구에서는 지도교수제에 대 한 사전 교육 없이 교수들이 학생들을 지도하고 있으며, 보완 대책 없이 방임 형태로 놓아둔 결과 학생들은 교수가 먼저 접 근하기를 바라고, 교수들은 학생들이 언젠가는 찾아와주기를 바라는 상태라고 보고하고 있다. 즉, 현행 지도교수제도는 그 취지와 목표에 맞지 않게 운영되고 있다는 것을 알 수 있다. 따라서 현행 지도교수제도가 그 목적과 목표에 맞게 학생들 에게 실질적인 도움이 되는 체계적인 지도교수제도 또는 멘 토링 프로그램 개발이 필요할 것이다.

둘째, 지도교수는 학생들과 밀접한 관계 속에서 바람직한 의사로서의 태도를 제시하기 위해서 자신이 실제적인 역할모 델이 되어야 하며, 학생들은 이런 교수의 역할모델을 보면서 동일시 과정을 통해 스스로의 태도와 행동 방식에 적용하며 전문가로서의 정체성을 형성하도록 도와주는 태도교육이 필 요하다. 따라서 학습과 진로에 대한 멘토링뿐만 아니라 인성 과 태도에 대해서도 동일한 수준으로 강조하는, 보다 복합적 이면서도 다양한 유형의 멘토링이 제공될 수 있는 모형이 개 발되어야 할 것이다.

셋째, 의료현장에서는 '전인적 의료(holistic health)'라는 말이 자주 쓰이는데, 이는 한 사람의 총체적인 건강(wellbeing)에 영향을 주는 모든 잠재적인 요소들을 고려한 의료 서비스를 의미한다[33]. 교육현장에서도 'holistic education' 이라는 용어가 많이 사용되는데, 전인적 교육은 개개인의 정 체성, 삶의 의미와 목적을 사회와 자연과 세계와 연계시켜 그 가치를 규명하는 과정이다[34]. 즉, 학습자가 학습에 열정을 가지고 경험적이고 의미 있는 학습을 하는 과정인 것이다. 따 라서 교육현장에서의 전인적인 교수자의 역할은 통제하고 선 두에 서기보다는 '친구, 멘토, 촉진자, 여행 동반자'와 같은 의 미로 본다[35]. 이러한 의미에서 국내 의과대학에서는 지(知), 정(情), 의(意)를 모두 갖춘 '전인적 멘토링(holistic mentoring)'을 적용해보기를 제안한다.

결론적으로, 전인적 멘토링이란 정서적인 지지자의 역할을 대변하는 멘토가 일대일 또는 소수의 멘티들과 개별적이고 지속적이며 밀착된 관계를 맺으면서 멘티가 지, 정, 의를 총체 적이고 균형 있게 갖추도록 함으로써 멘티의 지속적인 성장 과 삶의 목표 실현을 돕는 과정으로 정의하고자 한다. 이러한
전인적 멘토링 프로그램을 의과대학생 또는 의학전문대학원 생 전학년에 걸쳐 적용할 수 있는 프로그램을 개발하고 이를 적용함으로써 '전인적 의료'를 실현할 수 있는 바람직한 의사 가 될 수 있도록 도와주고 이끌어줄 수 있을 것으로 기대한다.

Acknowledgements: None.

Funding: This work was supported by the National Research Foundation of Korea Grant funded by the Korean Government (NRF-2011-332-B00360).

Conflicts of interest: None.

\section{REFERENCES}

1. Hahm BJ. Urinara uigwadaehaksaeng jeongsinggeongang siltaewa gak daehakui gwalli hyeonhwang. Paper presented at: the 21st Korean Medical Education Conference; 2007 May 31-June 2; Busan, Korea.

2. Park CW, Park SH, Cho YR. The relationship between psychological characteristics and academic achievement in medical students. J Korean Neuropsychiatr Assoc 1999; 38: 985-996.

3. Ryu SH. Quality of life and depressive symptoms and suicidal ideation in medical college students. J Soonchunhyang Med Sci 2009; 14: 149-158.

4. Han SS, Lee SY, Choi WS, Kim SJ, Park SB, Lee SY. Depression and its influencing factors among Korean medical and engineering students in urban areas using Zung self-rating depression scale. Korean J Fam Med 2009; 30: 539-548.

5. Lee CI, Hong SC, Kim HJ, Kim MD. Prevalence of severe distress and its correlates among Cheju Medical College students. Korean J Med Educ 2007; 19: 235-249.

6. Saipanish R. Stress among medical students in a Thai medical school. Med Teach 2003; 25: 502-506.

7. Frank E, Carrera JS, Elon L, Hertzberg VS. Predictors of 
US medical students' prevention counseling practices. Prev Med 2007; 44: 76-81.

8. Shin HI, Jeon WT. "I'm not happy, but I don't care": help-seeking behavior, academic difficulties, and happiness. Korean J Med Educ 2011; 23: 7-14.

9. Buddeberg-Fischer B, Herta KD. Formal mentoring programmes for medical students and doctors: a review of the Medline literature. Med Teach 2006; 28: 248-257.

10. Frei E, Stamm M, Buddeberg-Fischer B. Mentoring programs for medical students: a review of the PubMed literature 2000-2008. BMC Med Educ 2010; 10: 32.

11. Hur SW, Kim HS, Son JY, Bae WK, Yoo TW, Lee YJ. The effect of lifestyle modification program for medical students' personal health practices. Korean J Fam Med 2009; 30: 277-284.

12. Ahn D, Park G, Baek KJ, Chung SI. Academic motivation, academic stress, and perceptions of academic performance in medical students. Korean J Med Educ 2007; 19: 59-71.

13. Coates WC, Crooks K, Slavin SJ, Guiton G, Wilkerson L. Medical school curricular reform: fourth-year colleges improve access to career mentoring and overall satisfaction. Acad Med 2008; 83: 754-760.

14. Lee KH, Ko Y, Kang KH, Lee HK, Kang J, Hur Y. Mental health and coping strategies among medical students. Korean J Med Educ 2012; 24: 55-63.

15. Benigni MD, Petrosky S. Mentoring matters: a toolkit for organizing and operating student advisory programs. Lanham, USA: Rowman \& Littlefield Education; 2011.

16. Johnson WB. On being a mentor: a guide for higher education faculty. Mahwah, USA: Lawrence Erlbaum Associates; 2007.

17. International Mentoring Association. Mentoring glossary [Internet]. Farmington, USA: International Mentoring Association; c2012 [updated 2010 October 20; cited 2012 August 5]. Available from: http://mentoring-association. org/resources/mentoring-glossary/.
18. Chung SJ, Kim JY, Oh YH, Suh DH, Kim YI. A study for improvement of faculty mentoring program in Gachon Medical School. Korean J Med Educ 2001; 13: $79-90$.

19. Garmel GM. Mentoring medical students in academic emergency medicine. Acad Emerg Med 2004; 11: 13511357.

20. Shea GF, Gianotti SC. Making the most of being mentored: mentors help, mentees do. 2nd ed. [place unknown]: Axzo Press; 2009. p 9-10.

21. Korea National Institute for Special Education. The dictionary of special education. Seoul, Korea: Korea National Institute for Special Education; 2009.

22. Lee SH. Influences of mentoring program on adjustment to college life and self-esteem in nursing college students. J Korean Acad Nurs Admin 2006; 12: 247-254.

23. Souba WW. Mentoring young academic surgeons, our most precious asset. J Surg Res 1999; 82: 113-120.

24. Ramanan RA, Phillips RS, Davis RB, Silen W, Reede JY. Mentoring in medicine: keys to satisfaction. Am J Med 2002; 112: 336-341.

25. Kram KE. Mentoring at work: developmental relationships in organizational life. Glenview, USA: Scott, Foresman; 1985.

26. Feldman MD. Faculty mentoring toolkit: UCSF faculty mentoring program. San Francisco, USA: The Regents of the University of California; 2009.

27. Harvard Business School. Coaching and mentoring: how to develop top talent and achieve stronger performance. Boston, USA: Harvard Business School; 2004.

28. Ensher EA, Murphy SE. Power mentoring: how successful mentors and protégés get the most out of their relationships. San Francisco, USA: Jossey-Bass; 2005.

29. Gurney E. Mentoring in medical school and other health professional schools: guidelines for mentees. New York, USA: NYU Medical Center/School of Medicine; 2010.

30. Lee HJ, Lee HS, Kwon JH. Mentoring need analysis and 
the model development for the adult learner in distance education. J Lifelong Educ 2006; 12: 279-306.

31. Kan JS. A study of development of a mentoring model in the university [dissertation]. [Chuncheon, Korea]: Kangwon National University; 2011.

32. Ahn DS. Korea daehakgyo uigwadaehakui jido gyosuje yeongu. Yonsei J Med Educ 2000; 2: 71-78.

33. Wikipedia. Holistic health [Internet]. [place unknown]: Wikipedia; c2003 [updated 2003 October 9; cited 2012 August 5]. Available from: http://en.wikipedia.org/wiki/
Holistic_health.

34. Scott HF, Robin AM. What holistic education claims about itself: an analysis of holistic schools' literature. Paper presented at: American Education Research Association Annual Conference; 2004 April; San Diego, USA.

35. Forbes SH. Values in holistic education. Paper presented at: the 3rd Annual Conference on Education, Spirituality and the Whole Child; 1996 June 28; London, UK. 
Appendix 1. Academic Mentoring Model

지원 체제
- 면학분위기 조성
• 멘토링 커뮤니시스템 확충
- 멘토링 시설(강의실, 수업지원실 등)
- 선발형태의 다양화
- 인센티브 부여(멘티의 인센티브, 활동비, 워
크숍, 통학생의 배려 등)
- 홍보 강화(학과카페, 모범사례, 홍보대사 활
용 등)
- 다양한 평가(팀 간 수업 참가에 의한 평가
요구)
- 멘토링 참여 확대
- 멘토링 과목 확장(실습 및 현장체험, 공동 작
품 활동 등)
- 멘토링 과목 통섭 수업(타과와의 공유)
- 멘토링 기간 연장
- 슈퍼바이저제(멘토 관리자) 도입
- 멘토의 사전 교육 강화
- 멘티 간 경쟁 필요
- 멘토링 그룹 간의 교류

\begin{tabular}{|c|c|c|}
\hline $\begin{array}{l}\text { - 학습령 제고 } \\
\text {-취업률 제고 }\end{array}$ & $\longleftarrow$ 기대 효과 & $\begin{array}{l}\text { - 학슴ㄹㅕㅕ 제고 } \\
\text { - 재학률 제고 }\end{array}$ \\
\hline $\begin{array}{l}\text { - 지식 전수 } \\
\text {-교수 경험 } \\
\text { - 장학금 혜택 } \\
\text { - 관련과목 성적 향상 }\end{array}$ & $\longleftarrow$ 참여 목적 & $\begin{array}{l}\text { - 관련 과목 성ㅈㅓㅓ 향상 } \\
\text { - 학습방법 습득 }\end{array}$ \\
\hline $\begin{array}{l}\text { - 신뢰성 향상 } \\
\text { - 멘토 자질 향상 } \\
\text { - 발표력 향상 } \\
\text { - 책임감 향상 } \\
\text { - 리더십 강화 } \\
\text { - 의사소통력 향상 } \\
\text { - 어휘력 향상 } \\
\text { - 사회성 제고 }\end{array}$ & $\longleftarrow$ & $\begin{array}{l}\text { - 학습력 향상 } \\
\text { - 의사소통격 향상 } \\
\text { - 자기 주도적 학습자 } \\
\text { - 자신의 학습 노트 작성 가능 } \\
\text { - 사회성 제고 }\end{array}$ \\
\hline $\begin{array}{l}\text { - 티칭 } \\
\text { - 인관관계 형성 } \\
\text { - 함습지원 } \\
\text { - 학습법 상담 } \\
\text { - 멘티의 교육적 성과 } \\
\text { - 선후배 간의 유대감 상승 } \\
\text { - 자율적인 참여 }\end{array}$ & $\leftarrow$ & 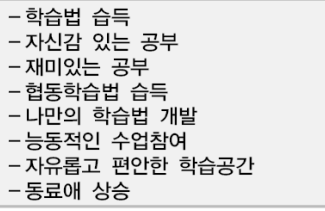 \\
\hline $\begin{array}{l}\text { - 선후배들 간의 교류 } \\
\text { - 장학금 지원 } \\
\text { - 구성원의 추천 }\end{array}$ & $\longleftarrow$ 참여 동기 & $\begin{array}{l}\text { - 학습력 제고 } \\
\text { - 선배, 친구의 도움 필요 } \\
\text {-편입 및 복학으로 히ㄱㅡㅡㅁㅇㅢ 어려움 해소 } \\
\text { - 멘토링 참여자의 조언 } \\
\text { - 동료와 함께 공부 희망 } \\
\text { - 멘토링의 효과성으로 지속 지원 }\end{array}$ \\
\hline 멘토 & 요소 & 멘티 \\
\hline
\end{tabular}

Adapted from Kan JS. A study of development of a mentoring model in the university [dissertation]. [Chuncheon, Korea]: Kangwon National University; 2011 [31].

\section{Appendix 2. Career Mentoring Model}
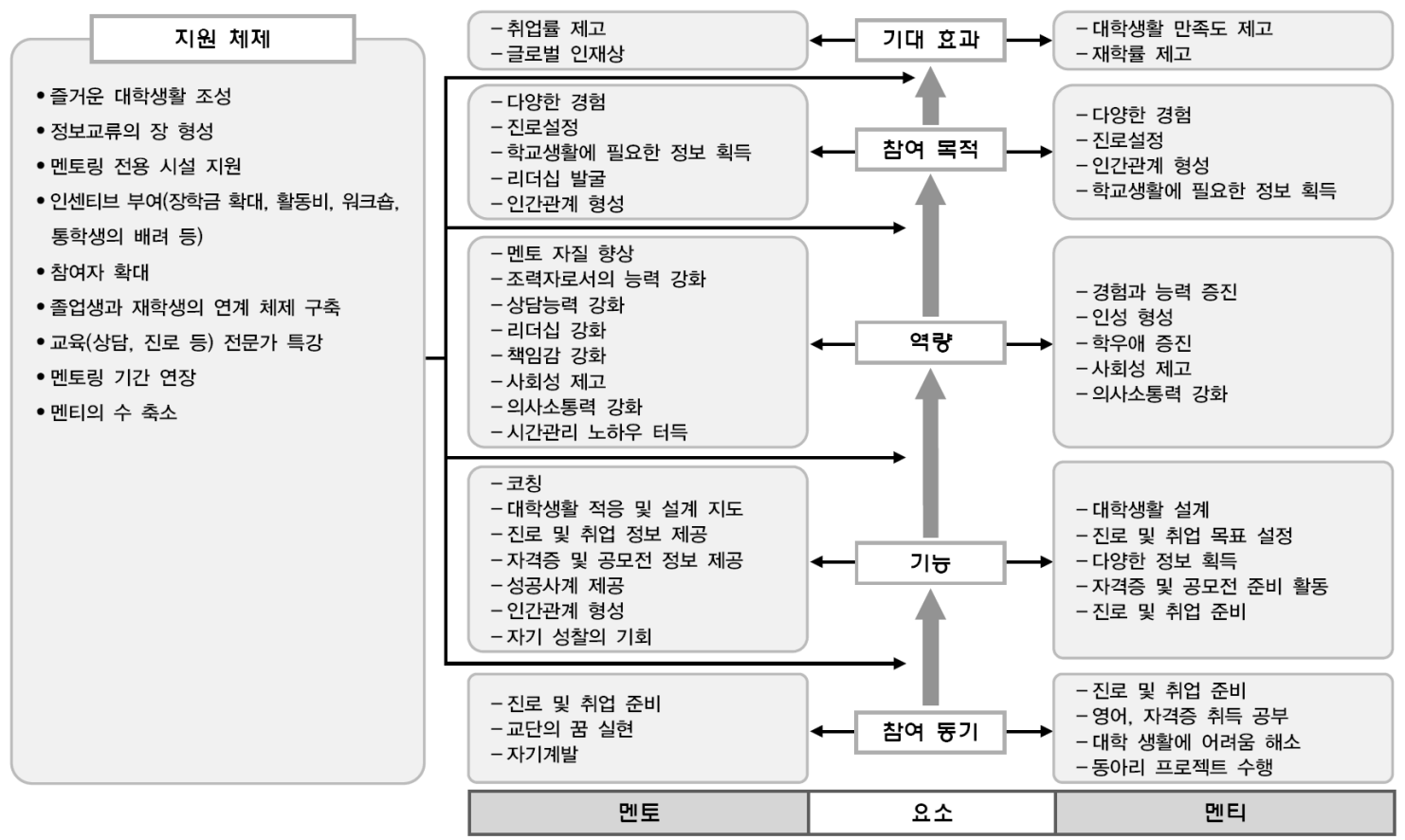

Adapted from Kan JS. A study of development of a mentoring model in the university [dissertation]. [Chuncheon, Korea]: Kangwon National University; 2011 [31]. 